\title{
FDA-approved small-molecule kinase inhibitors
}

\author{
Wu, Peng; Nielsen, Thomas E.; Clausen, Mads Hartvig
}

Published in:

Trends in Pharmacological Sciences

Link to article, DOI:

10.1016/j.tips.2015.04.005

Publication date:

2015

Document Version

Peer reviewed version

Link back to DTU Orbit

Citation (APA):

Wu, P., Nielsen, T. E., \& Clausen, M. H. (2015). FDA-approved small-molecule kinase inhibitors. Trends in Pharmacological Sciences, 36(7), 422-439. https://doi.org/10.1016/j.tips.2015.04.005

\section{General rights}

Copyright and moral rights for the publications made accessible in the public portal are retained by the authors and/or other copyright owners and it is a condition of accessing publications that users recognise and abide by the legal requirements associated with these rights.

- Users may download and print one copy of any publication from the public portal for the purpose of private study or research.

- You may not further distribute the material or use it for any profit-making activity or commercial gain

- You may freely distribute the URL identifying the publication in the public portal

If you believe that this document breaches copyright please contact us providing details, and we will remove access to the work immediately and investigate your claim. 
(A)

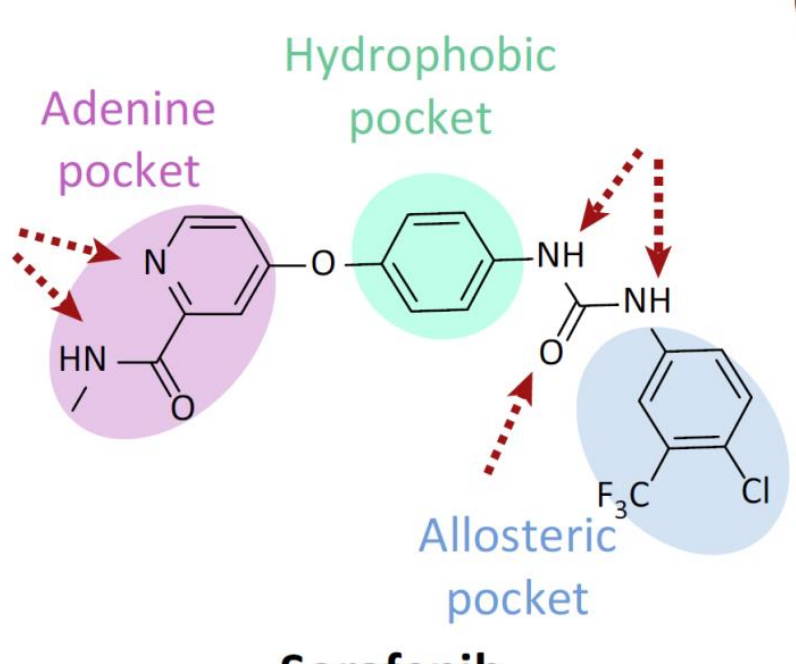

Sorafenib

(D)

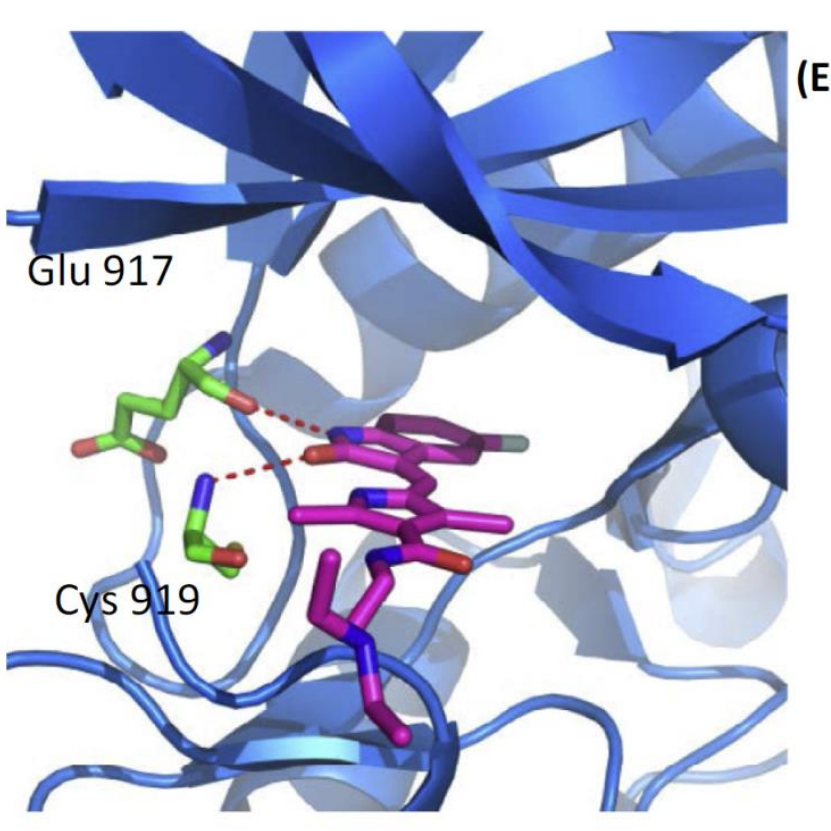

(B)

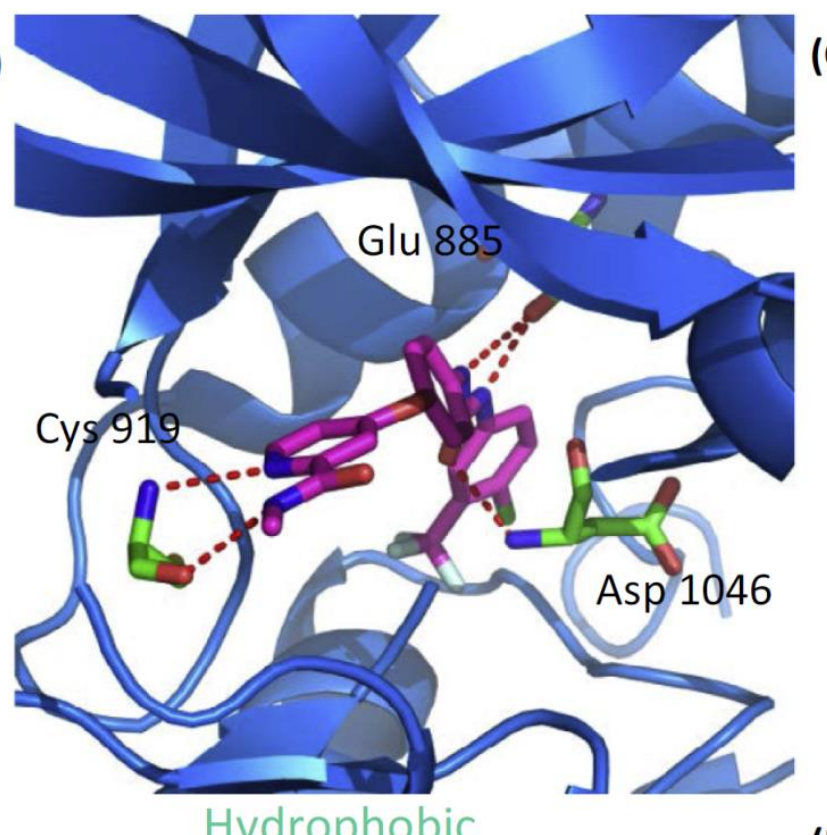

(E)

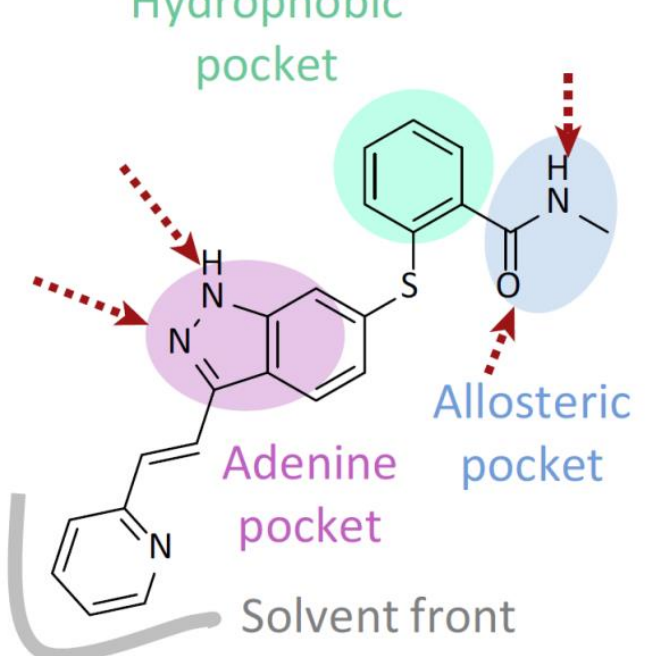

Axitinib

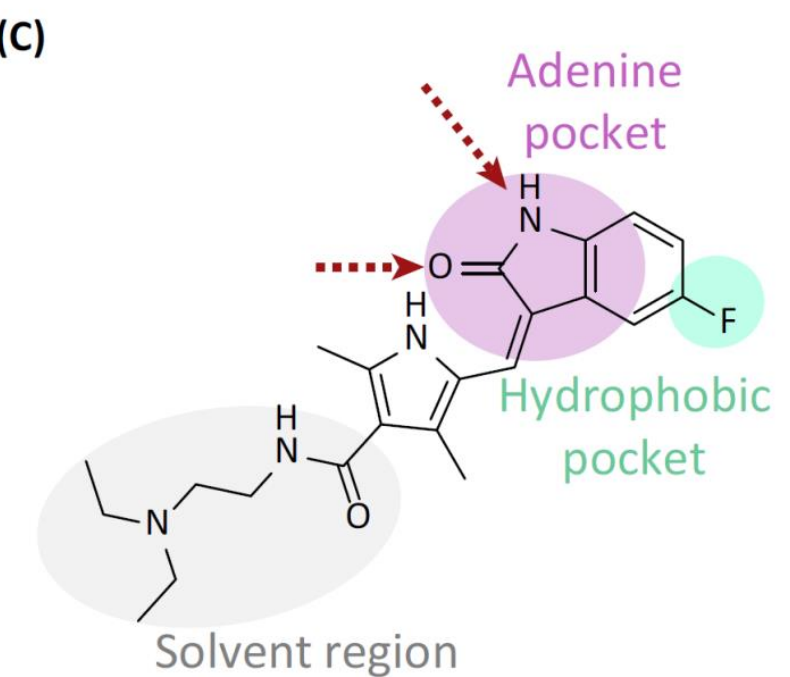

Sunitinib

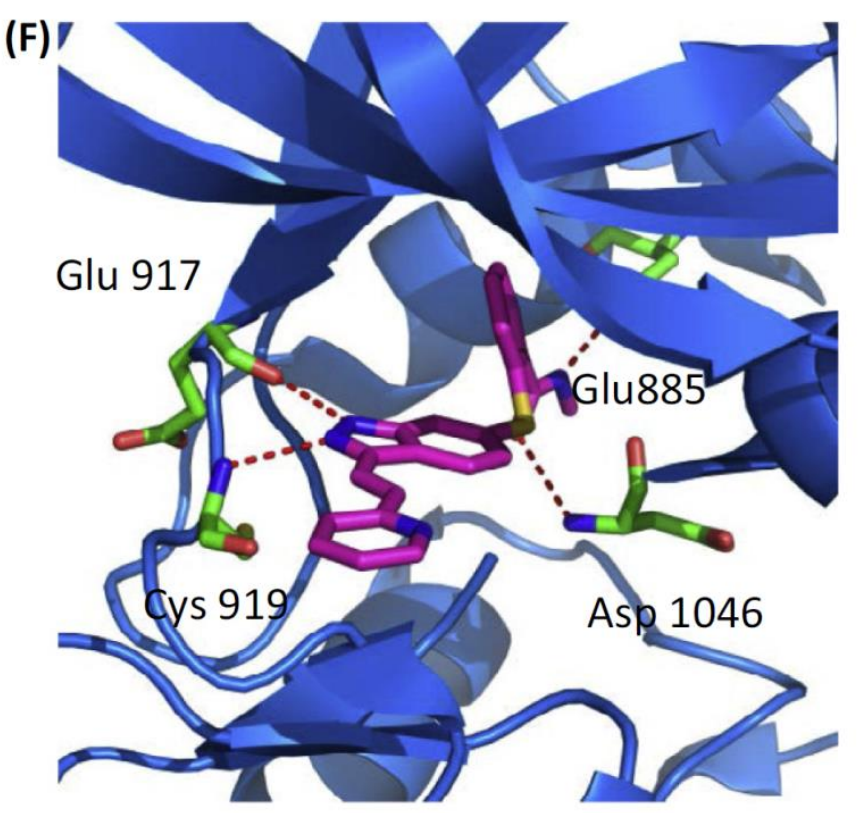

(H)

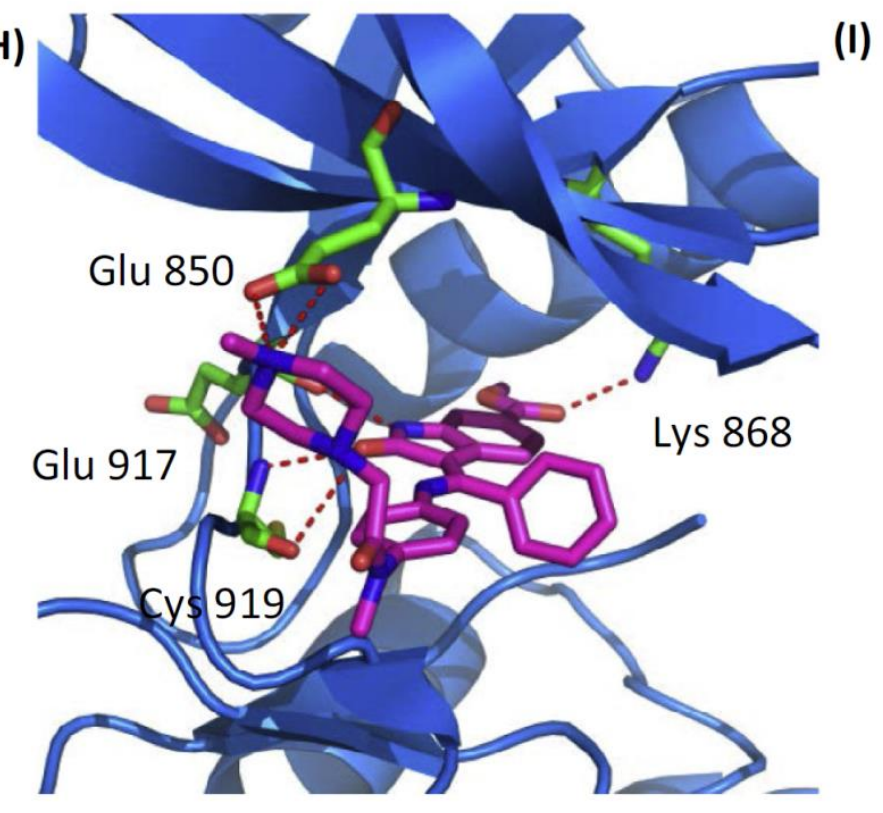

(I)

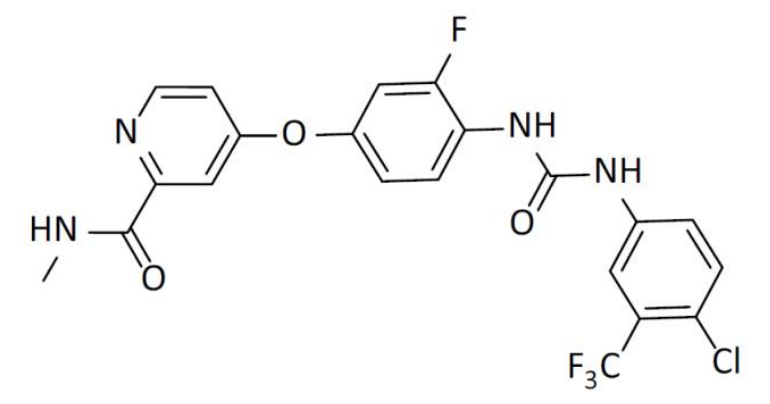

Regorafenib

(J)

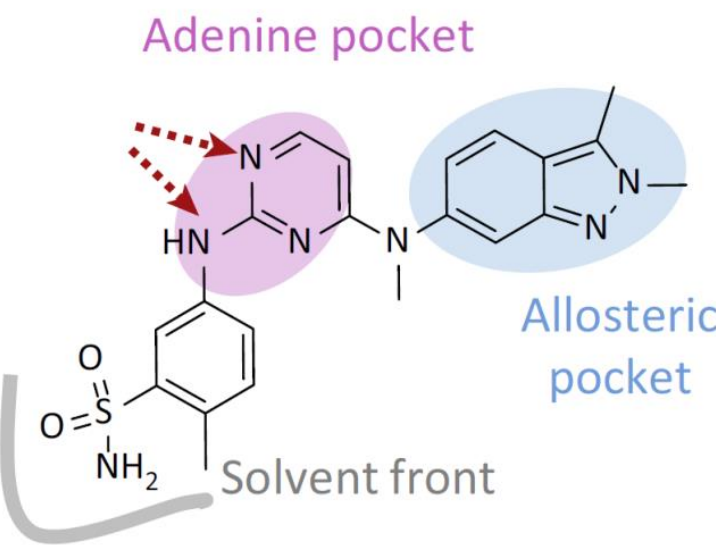

Pazopanib
(K)

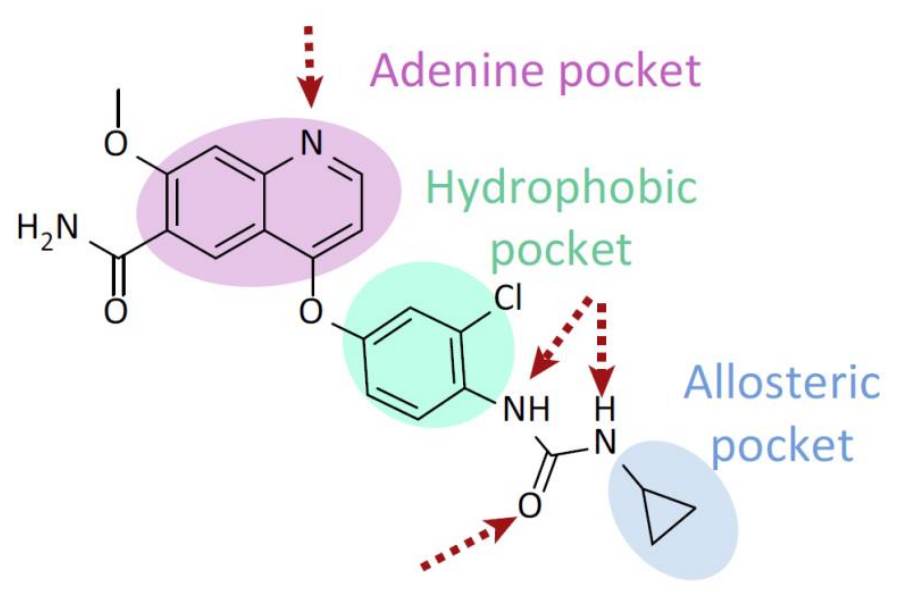

Lenvatinib 
(A)

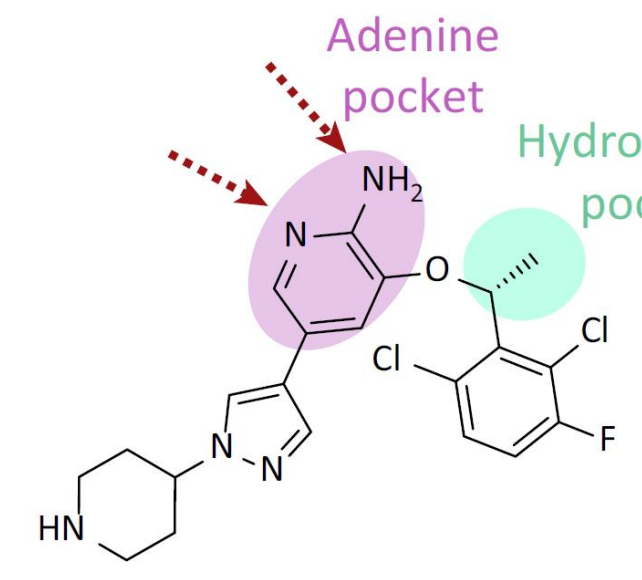

\section{Crizotinib}

(D)

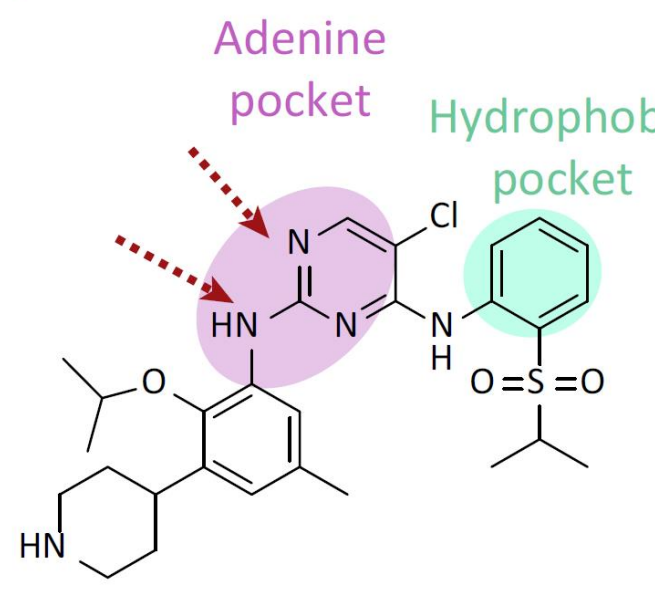

Ceritinib
(B)
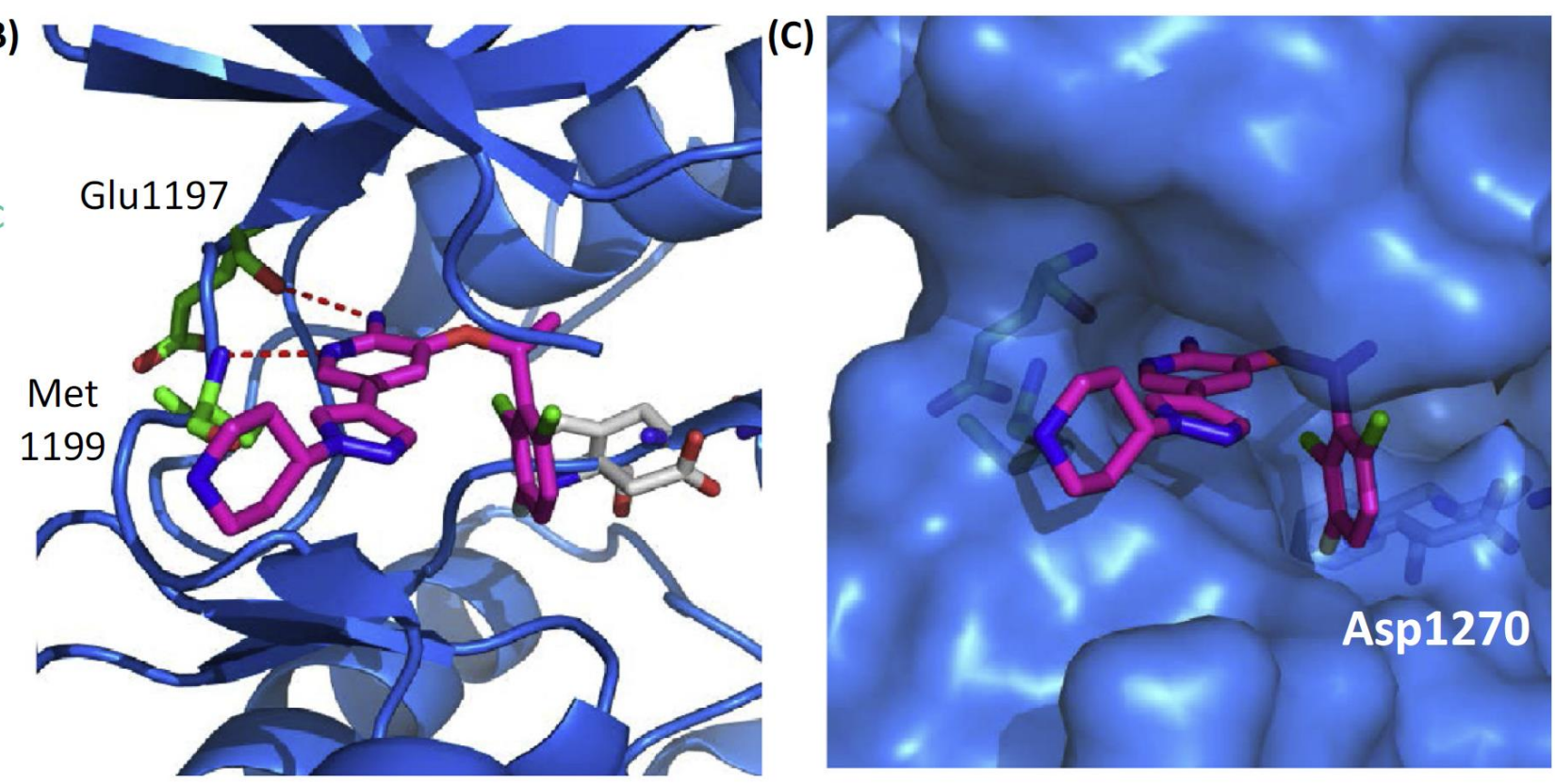

(E)
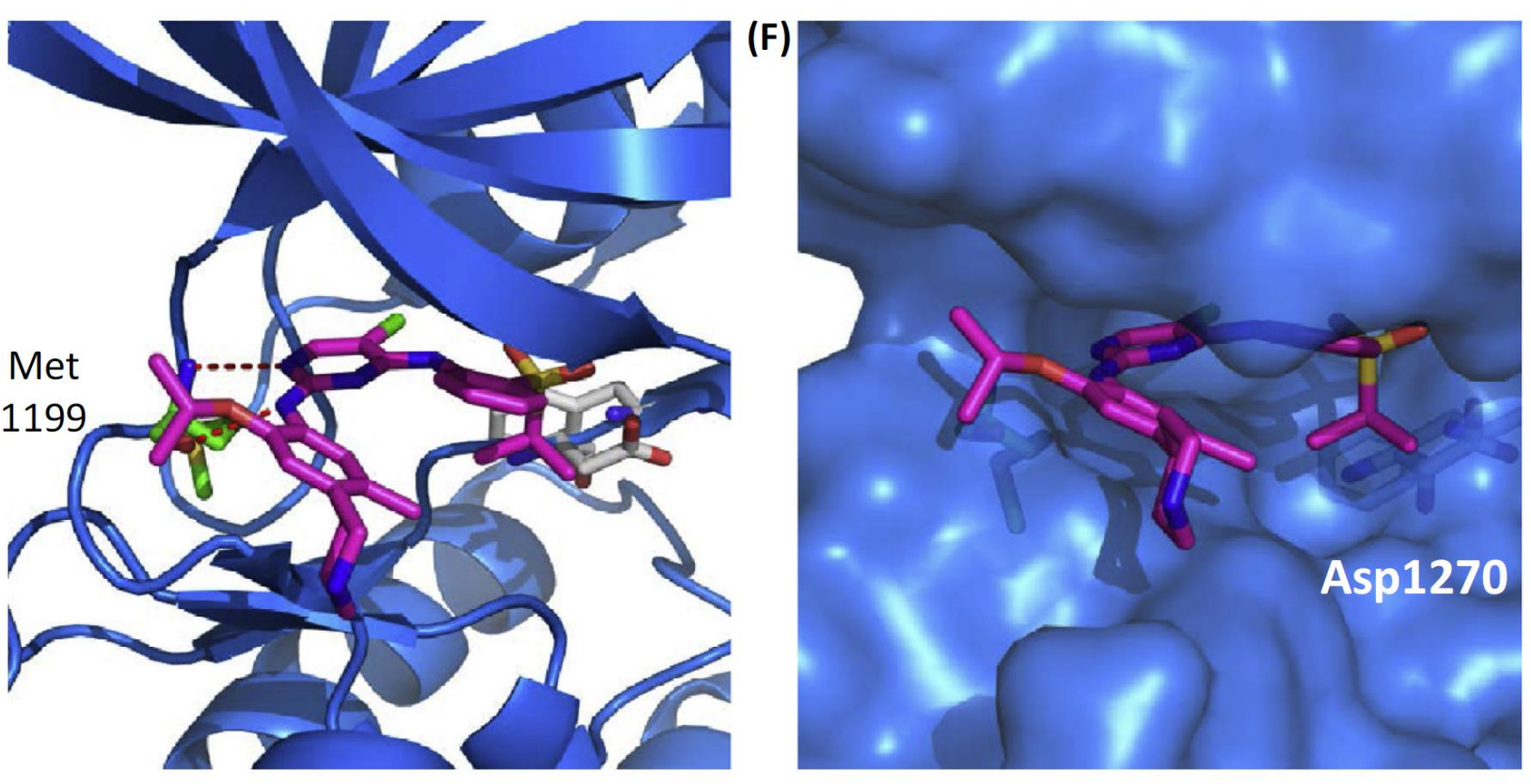
(A)

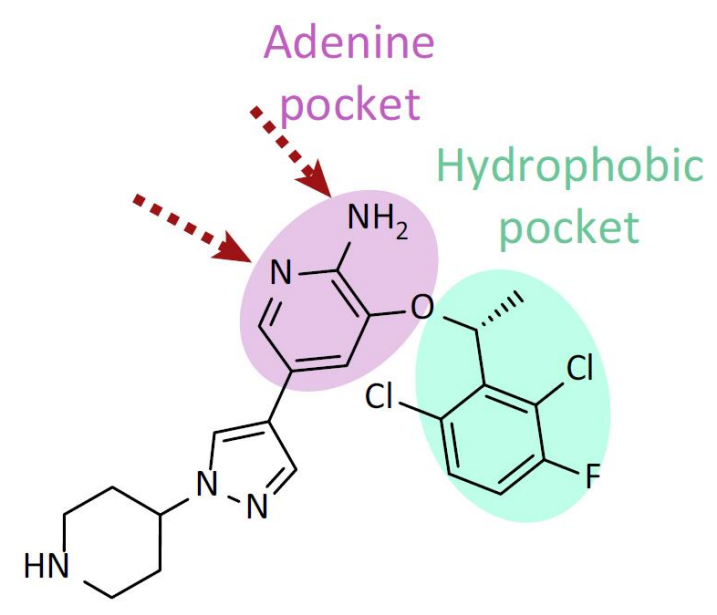

Crizotinib

(D)

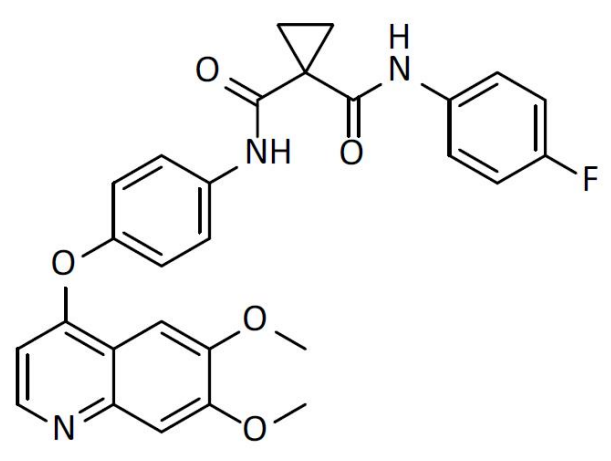

Cabozantinib

(G)

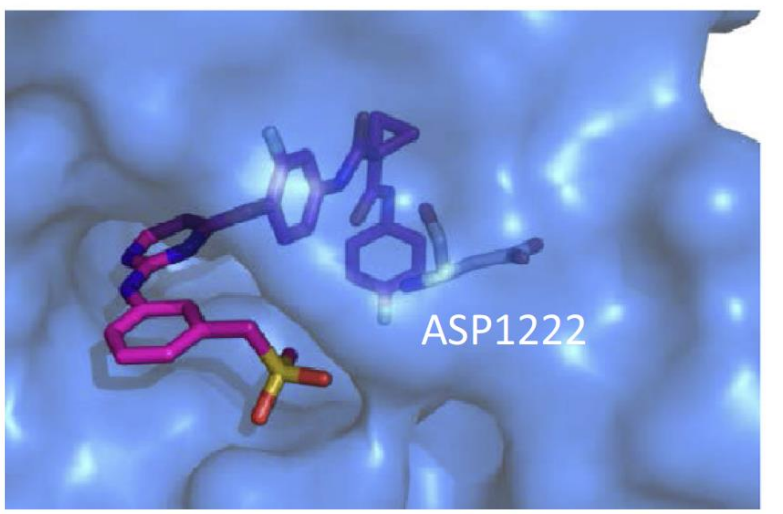

(E)
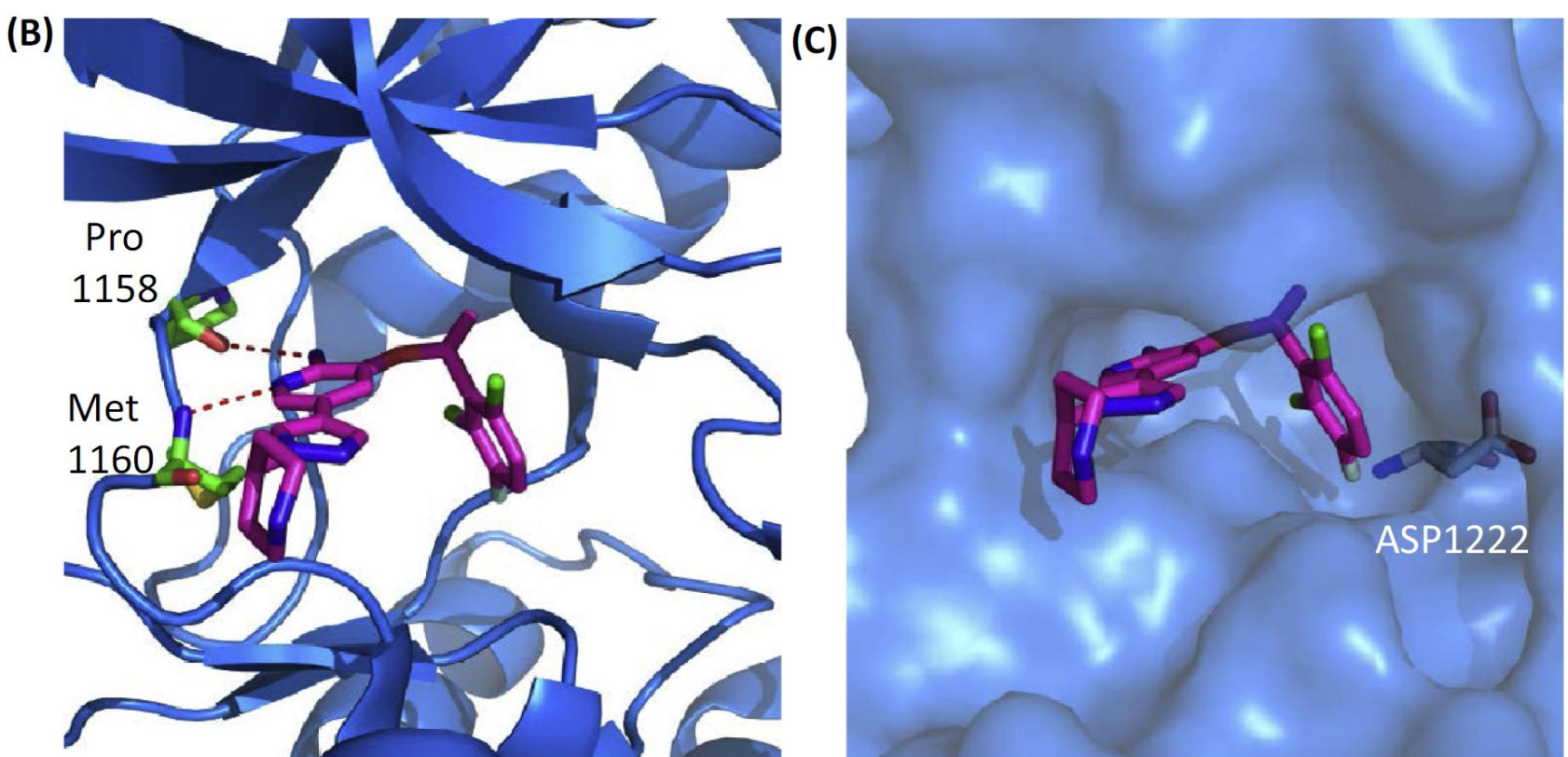

Allosteric

channel
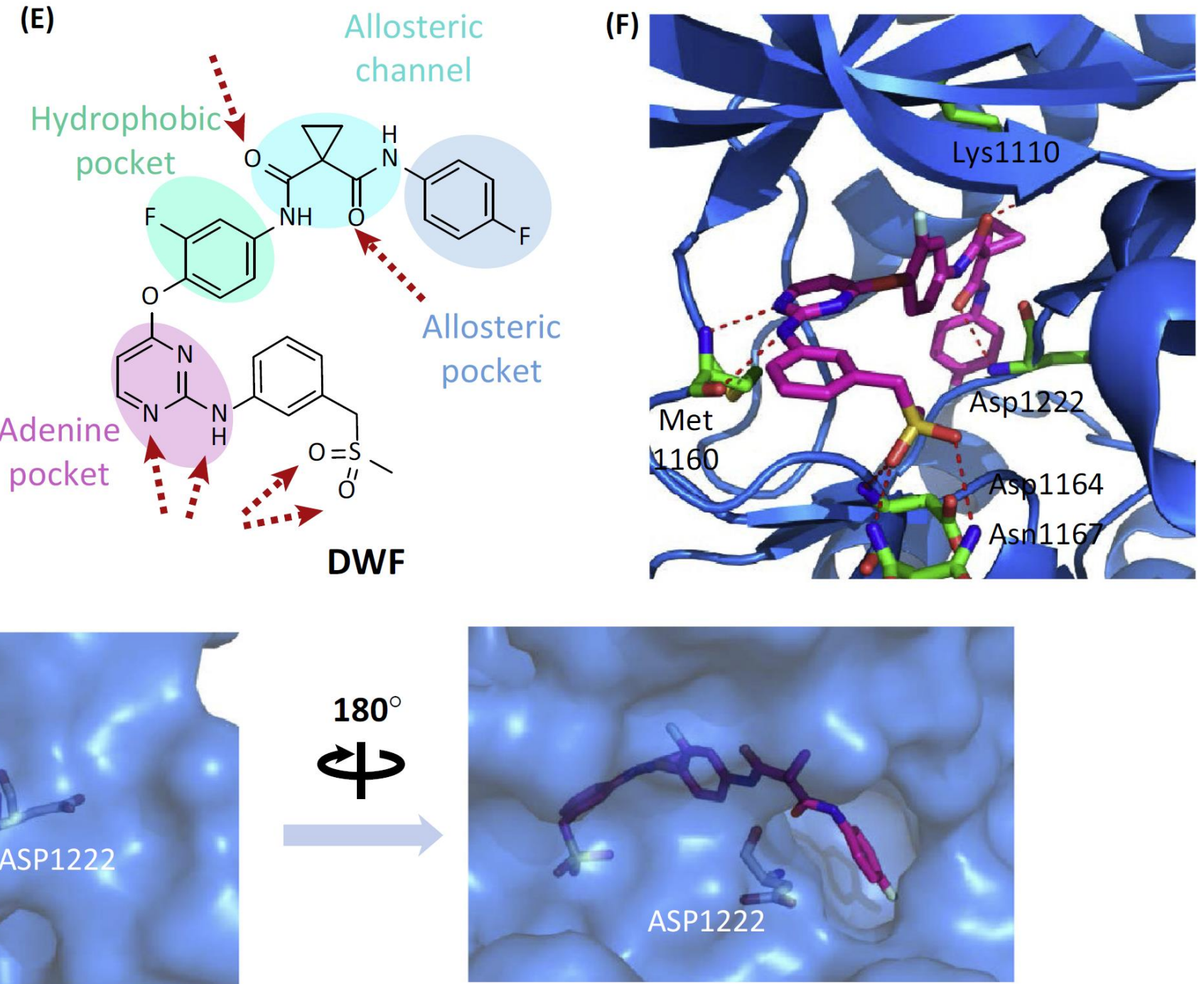
(A)

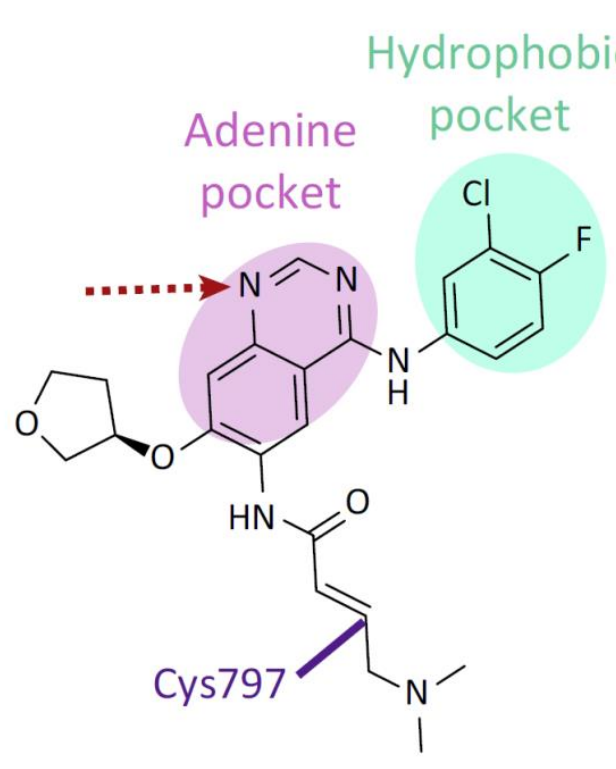

Afatinib

(D)

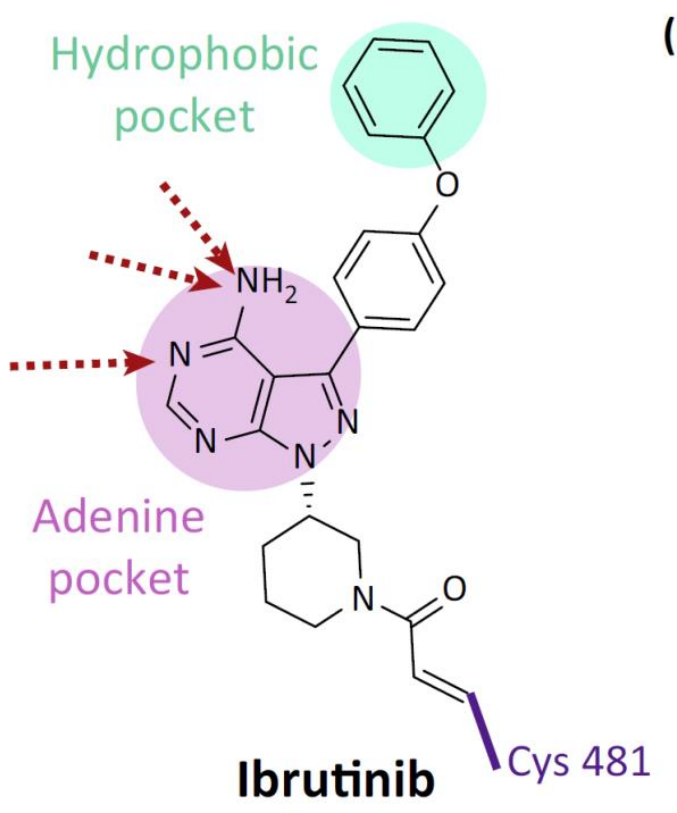

(B)

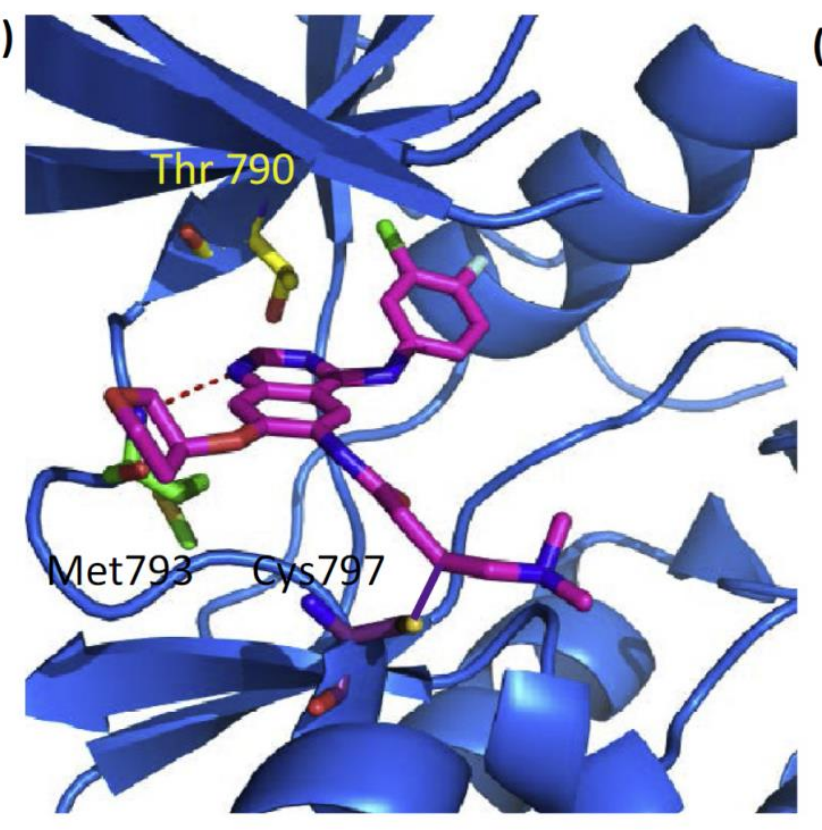

(E)

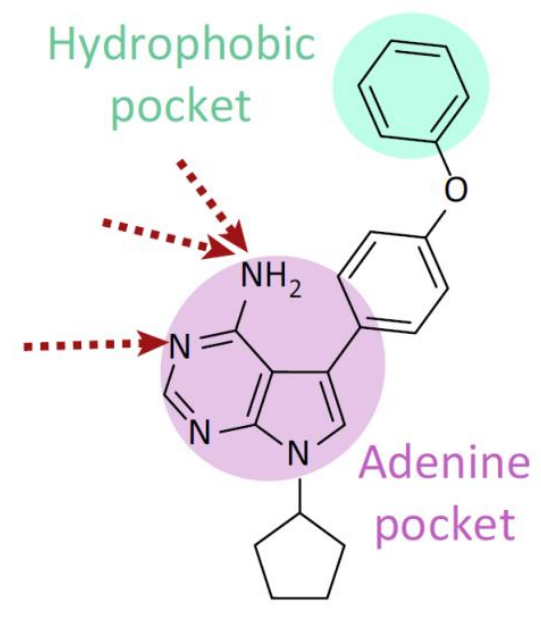

B43

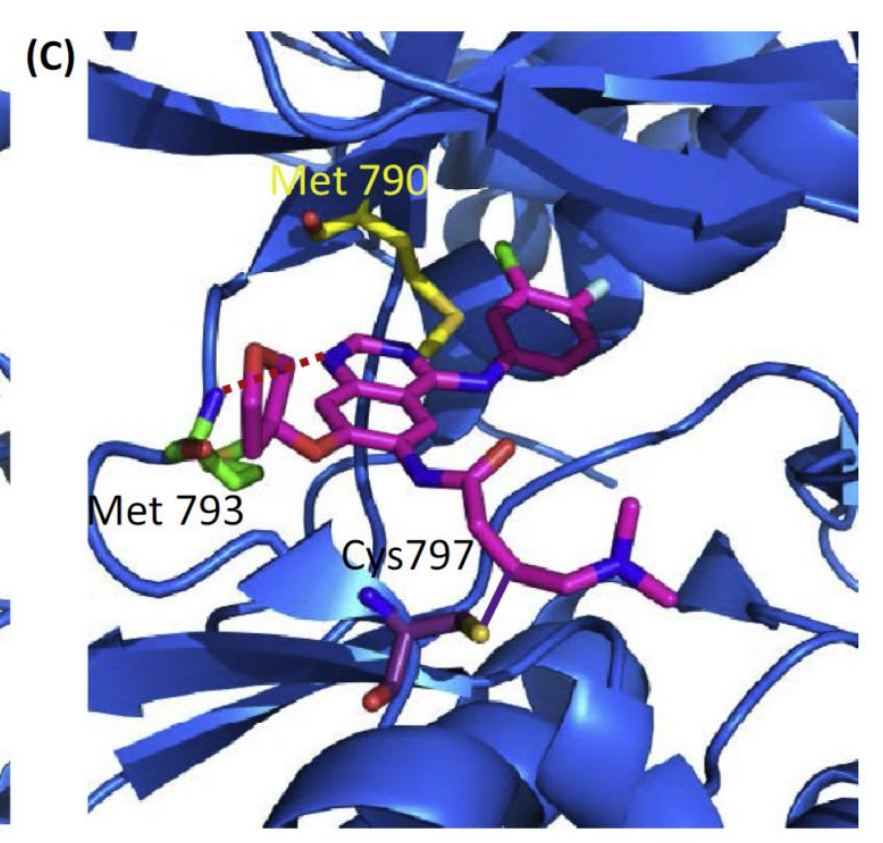

(F)

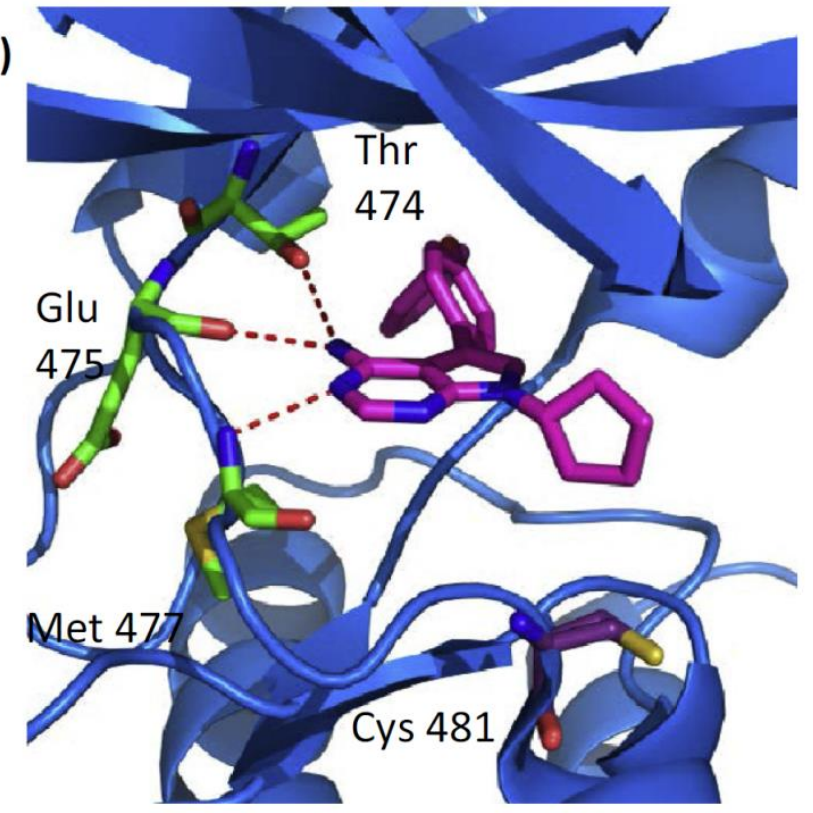


(A)

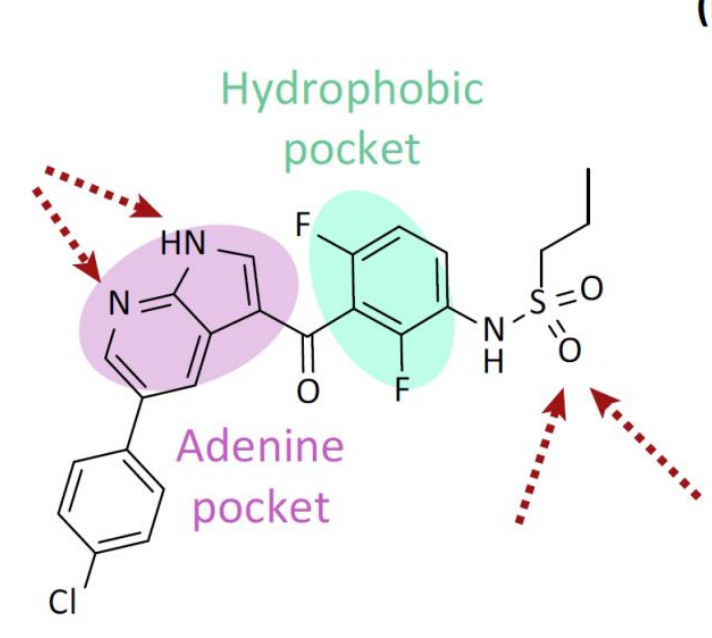

\section{Vemurafenib}

(D)<smiles>CC(C)(C)c1nc(-c2cccc(NS(=O)(=O)c3c(F)cccc3F)c2F)c(-c2ccnc(N)n2)s1</smiles>

Dabrafenib
(B)

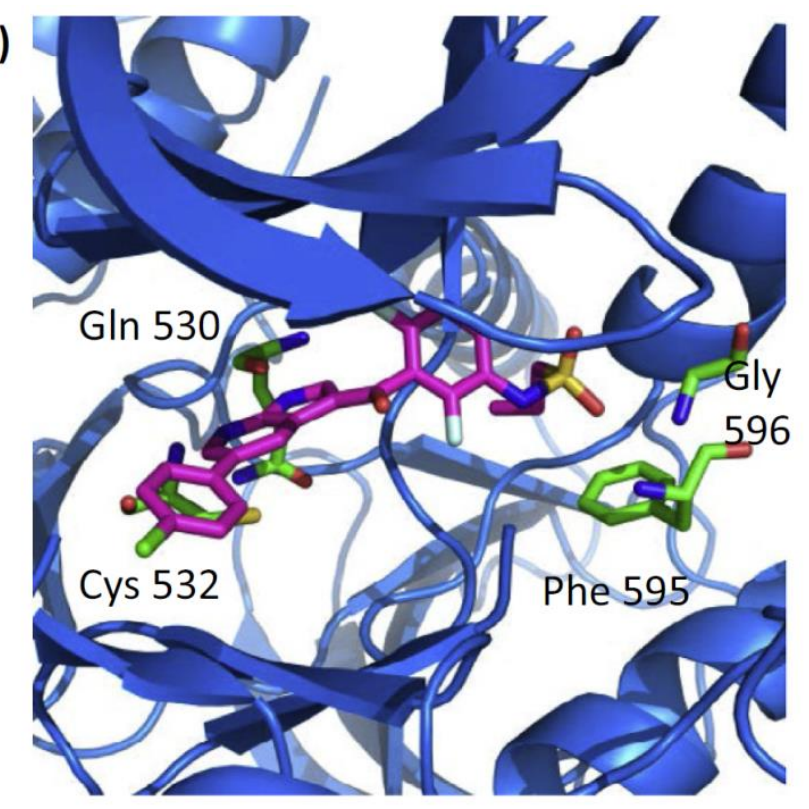

(E)

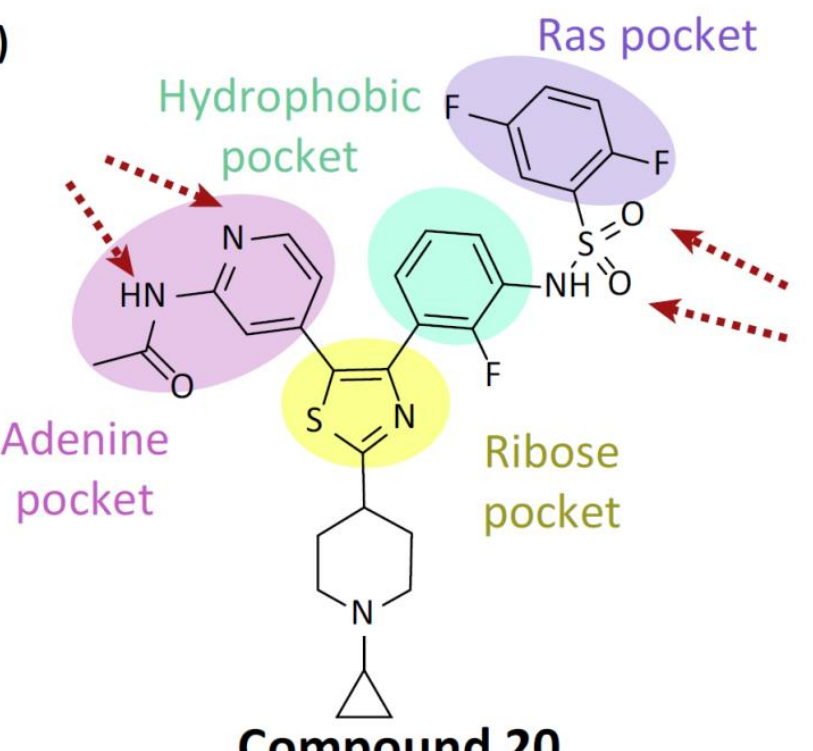

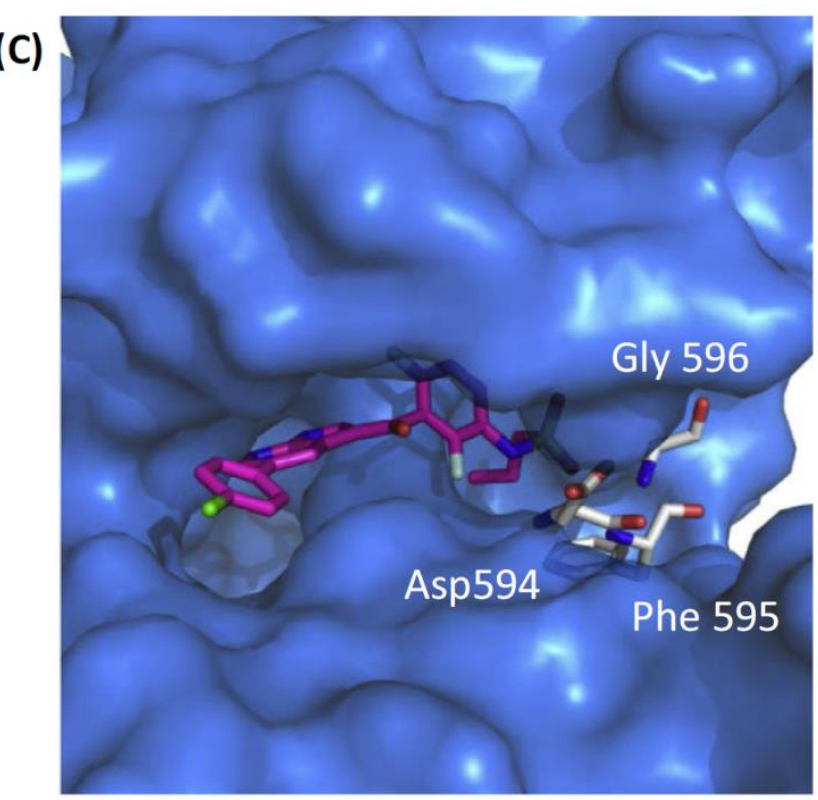

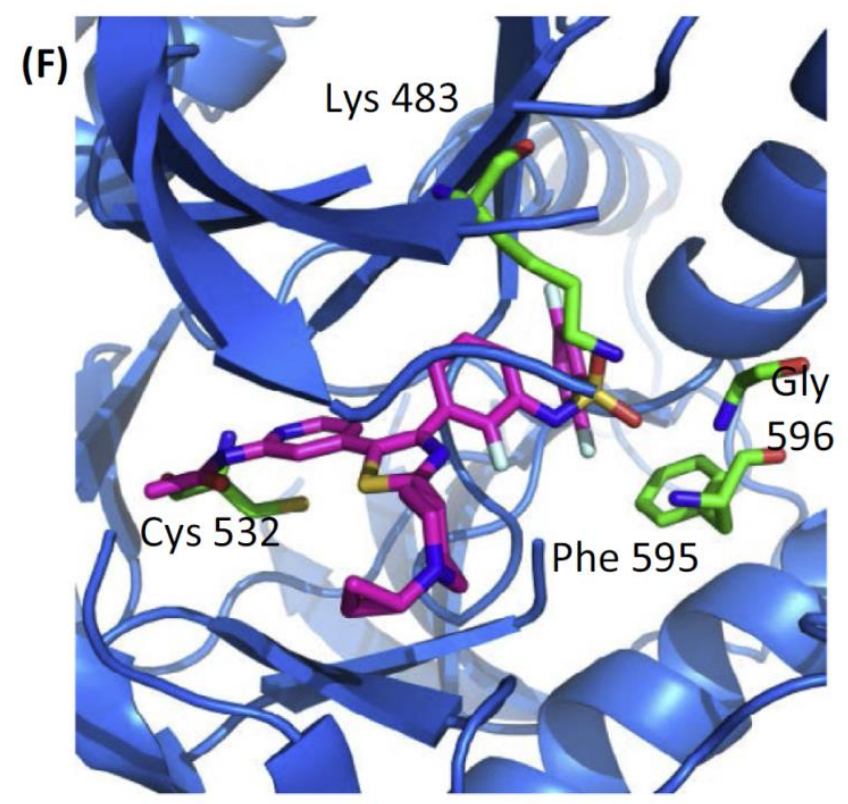

(G)

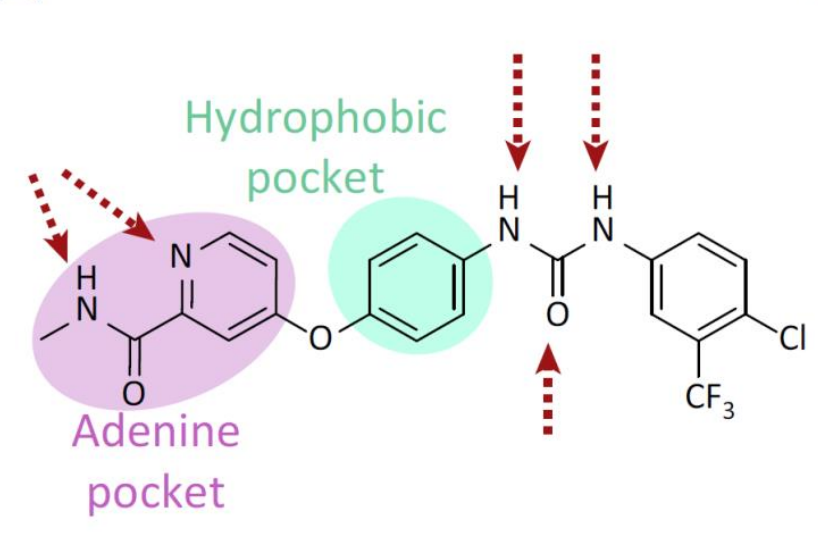

Sorafenib
(H)

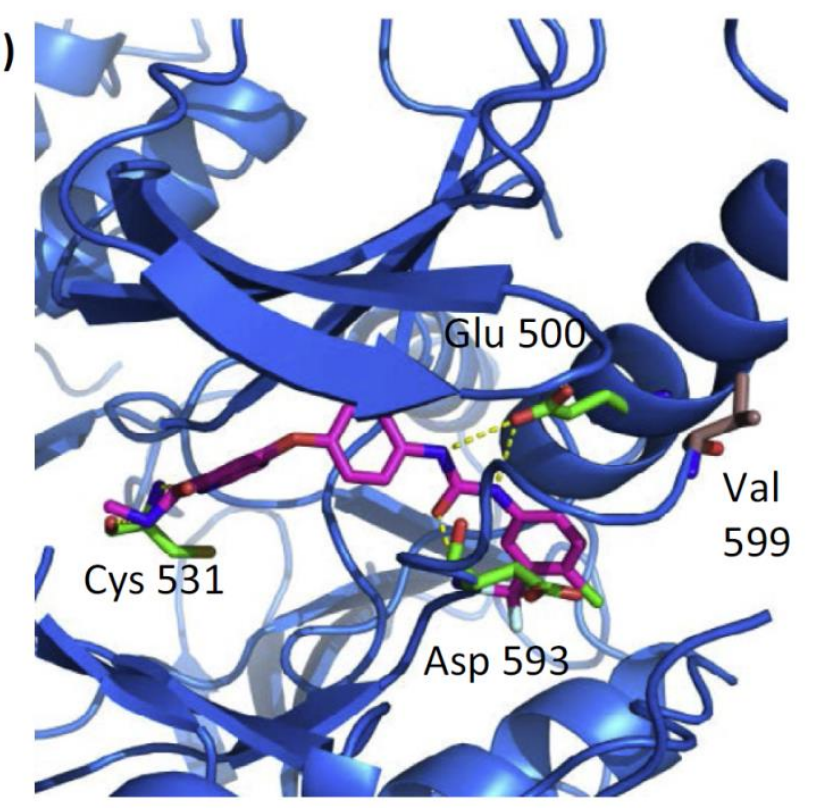

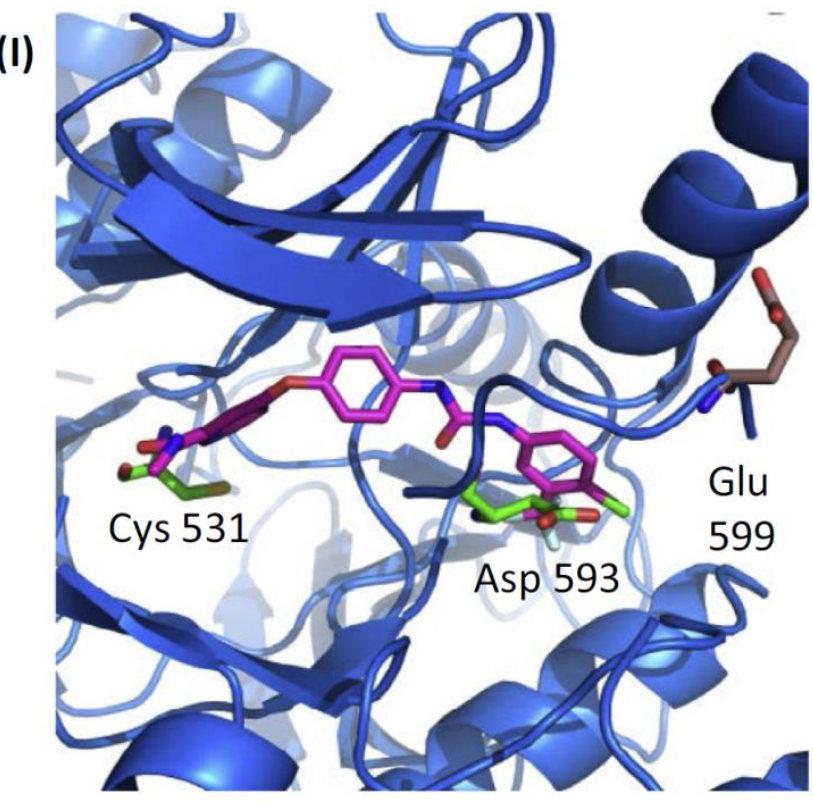


(A)

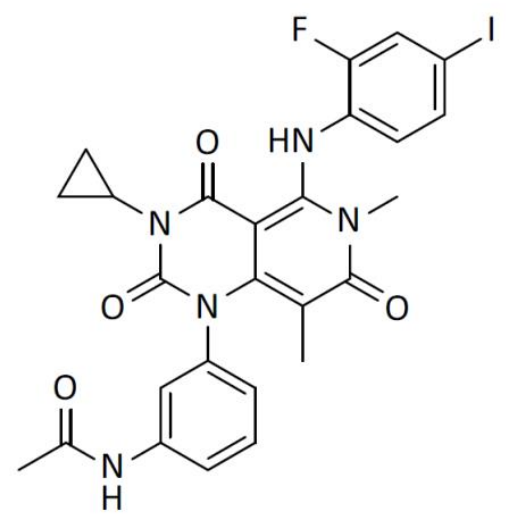

Trametinib
(B)

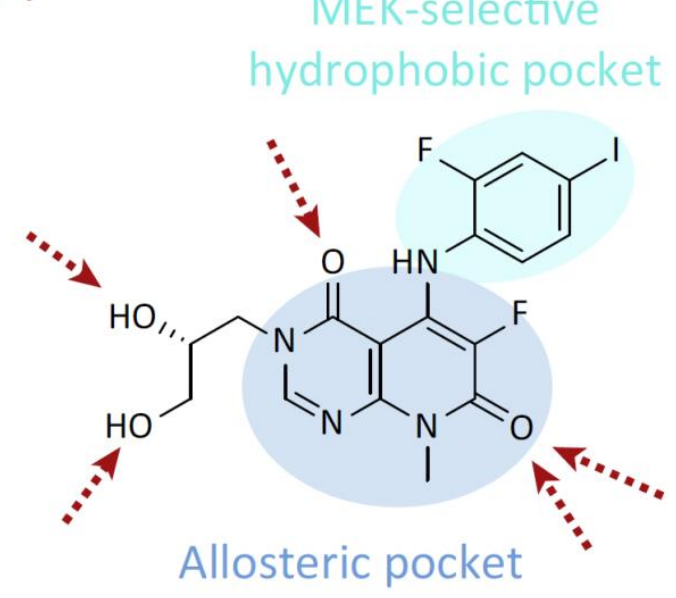

Tak-733
(C)

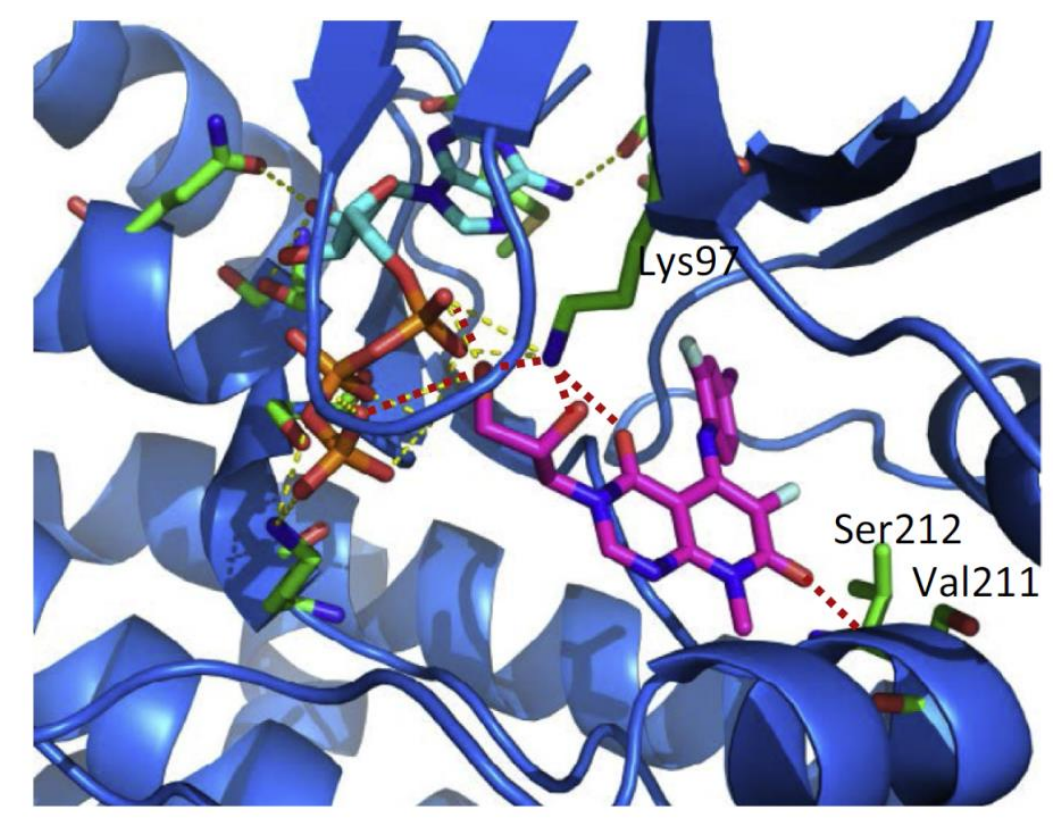

